\title{
Letter re: The exact number of misplacements is essential for the reproducibility of statistical findings by Mansoor et al.
}

\author{
Ghassan Kerry ${ }^{1} \mathbb{D}$
}

Received: 5 January 2021 / Accepted: 24 May 2021 / Published online: 11 June 2021

(c) The Author(s), under exclusive licence to Springer-Verlag GmbH Austria, part of Springer Nature 2021

Dear Editor,

I have read with interest the recent paper by Mansoor et al. [1]. The authors performed a retrospective study on accuracy and complication rates of external ventricular drain placement (EVD) with twist drill and bolt system versus standard trephine and tunnelation.

The reported number of tunnelated EVD-placements in Table 2 mismatches the given percentage in the same table. As the Text of the paper does not reflect the exact number of misplacements, there is no possibility to reproduce the published percentage of misplacements of tunnelated EVDs. A correction of the content of Table 2 is therefore essential.

This article is part of the Topical Collection on Neurosurgical technique evaluation

Ghassan Kerry

Ghassan.Kerry@Klinikum-Nuernberg.de

1 Department of Neurosurgery, Paracelsus Medical University, Breslauer Strasse 201, 90471 Nuremberg, Germany
With kind regards,

Dr. med. univ. Ghassan Kerry.

Department of Neurosurgery.

Paracelsus Medical University, Nuremberg, Germany.

\section{Reference}

1. Mansoor N, Madsbu MA, Mansoor NM, Trønnes AN, Fredriksli OA, Salvesen Ø, Jakola AS, Solheim O, Gulati S (2020) Accuracy and complication rates of external ventricular drain placement with twist drill and bolt system versus standard trephine and tunnelation: a retrospective population-based study. Acta Neurochir (Wien) 162(4):755-761. https://doi.org/10.1007/ s00701-020-04247-3

Publisher's Note Springer Nature remains neutral with regard to jurisdictional claims in published maps and institutional affiliations. 